\title{
Drug Hypersensitivity Syndrome
}

National Cancer Institute

\section{Source}

National Cancer Institute. Drug Hypersensitivity Syndrome. NCI Thesaurus. Code C112208.

A potentially life-threatening hypersensitivity reaction to a pharmacologic substance that is characterized by rash, lymphadenopathy, fever, hematologic abnormalities and involvement of one or more internal organs. 